\title{
A Pragmatic Research Report on Compliment Speech Act
}

\author{
Yuanbing Duan \\ Yunnan Radio and TV University, Kunming, 650223, China \\ Email: duanyuanbing@yahoo.com.cn
}

\begin{abstract}
This paper aims to raise second language cross-cultural pragmatic awareness by analyzing the complimenting speech act of Chinese EFL learner. The result necessitates a detailed explanation of the strategies that the learner makes use of when performing the speech act in different contexts of situations. The findings will provide very essential pedagogical implications in second language teaching, avoiding miscommunication as much as possible so as to reach the purpose of communication.
\end{abstract}

Index Terms - complimenting, speech acts, pragmatic awareness

\section{INTRODUCTION}

\section{A. Goal of the Project}

The paper seeks to investigate complimenting realization patterns in English of a Chinese EFL learner by means of statistical data as well as some prior theories so as to achieve two aims: what language forms do Chinese learners of English use to perform the speech act of compliment; in what way do they realize the English speech act of compliment? The result necessitates a detailed explanation of the strategies that Non Native Speakers (NNS) makes the use of when performing compliment in different contexts of situations.

According to Austin (1962), when we speak a language, we do not say the words for no purpose, actually, we use it for doing things as well. However, the thing that an utterance does in one language may be different from another language due to culture diversities.

Complimenting is a very common expressive speech act according to Searle (1975) which can be used to anyone, everyday and in many circumstances. As Holmes (1988) noted, a compliment is "a speech act which explicitly or implicitly attributes credit to someone other than the speaker, usually the person addressed, for some good (possession, characteristic, skill, etc.) which is positively valued by the speaker and the hearer" (p.485). It serves many functions, starting a conversation, keeping the conversation go smoothly, making a positive comment to someone for the purpose of maintaining solidarity among people. What a pity if we fail to achieve the above purposes by misusing compliments, which will lead to a breakdown of successful communications.

In fact, the speech act is composed of two parts: how to make compliments and how to respond to compliments. This paper deals with the former due to the length limitation.

By nature, this is a pragmatic attempt to find out the pragmatic strategies in a specific speech act. Therefore, the results and findings will provide some pedagogical implications in improving our ability of using English, avoiding miscommunication as much as possible so as to reach the purpose of communication.

\section{B. Literature Review}

Generally speaking, there are many studies done in compliment responses which are far more than realization patterns. The following are some relevant literatures with the latter, Nessa Wolfson and Joan Manes are main contributors in this field.

Wolfson (1983) summarized some major topics for complimenting. It falls into two major categories: appearance/possession and ability. One of the most striking aspects of American English compliments is the overwhelming number of compliments on personal appearance, most particularly clothes and hairdos. In addition, by far the most frequent types of compliments are those on addressee's skill or effort: such as a well-done job, a skillfully played game, and a good meal.

Moreover, Wolfson (1988) explained the most frequent exchanges of compliments are found between moderately close people. That is to say, very close people like family members do not exchange compliments as frequently, nor do those of slight acquaintance. It appears that women often had to exercise explicit compliments in order to get sufficient attention, on the contrary, males are not always been complimented (p.137).

In addition, one of the most striking features of compliments is remarkably formulaic. Formulaicity in speech is presumed to be a universal phenomenon, sometimes even native speakers do not aware it.

Manes \& Wolfson (1981) gathered six hundred and eighty-six compliments through observation of everyday interactions. The semantic, syntactic and discourse features of compliments formulae are examined, $97 \%$ of them consists the following nine patterns, which can be used as analytical framework in the data analysis part (p.120-121). 
1. NP \{is, looks $\}$ (really) ADJ PP

2. I (really) \{like, love $\}$ NP

3. PRO is (really) (a) (ADJ) NP

4. You V (a) (really) ADJ NP

5. You V (NP) (really) ADV PP

6. You have (a) (really) ADJ NP

7. What (a) (ADJ) NP!

8. ADJ (NP)!

9. Isn't NP ADJ!

Among these nine types, $80 \%$ of compliments in data are adjectival type, such as type 8, 3, 1, 4, and 6. Among them, $72 \%$ adjectives make up only five frequently used responses (nice $22.9 \%$, good $19.6 \%$, beautiful $9.7 \%$, pretty $9.2 \%$ and great $6.2 \%$ ). Besides adjectives, verbs are also used to carry positive semantic evaluation, such as type 2 and 5.

Politeness Principles has gained a lot of attentions. Brown \& Levinson's (1987) Face Threatening Acts (FTAs), is considered as the most powerful theories to explaining the realization of speech acts. Leech's Modesty Maxims (1983), is shown to be the most adequate model to analyze the data. He proposed that it is customarily more polite to find a compromise between violating the Modesty Maxim and violating the Agreement Maxim in English speaking societies. $\mathrm{Gu}$ (1990) compared western notion of face and politeness to Chinese ones, he pointed out four politeness maxims which are typical in Chinese cultures, attempted to demonstrate culture--specific and language -specific.

Chen (1993) found that American compliments and Chinese compliments use largely different politeness strategies: “the American English speakers' strategies are mostly motivated by Leech's Agreement Maxim, whereas the Chinese are motivated by his Modesty Maxim. This difference is then related to differences of social values between the two cultures, particularly in their respective beliefs about what constitutes self-image"(p.49).

Han (1992) did a comparative study on compliment speech acts in Korean and in English interactions. The act was realized and responded quite differently across cultures.

To sum up, this part reviews what favorable topics are in complimenting and its social distributions as well as its linguistic patterns. The findings provide me the sources for designing questionnaire (see Appendix) in present study. It also informed that the same complimenting speech acts will realize differently due to different cultural backgrounds and different language using rules. Communicative competence is the utmost goal for an EFL learner. To learn a foreign language well means not merely to master the pronunciation, grammar, words and idioms, but also to see the world as native speakers of that language see; to learn the ways in which their language reflects the ideas, customs, and behavior of their society; and to learn to understand their language of the mind. It is a very challenging job for teachers intensifying teaching on both linguistic and culture perspectives.

My research will shed new lights on the understanding complimenting realization patterns and its pragmatic strategies which are very important for us to improve our communicative competences.

\section{RESEARCH METHODOLOGY}

\section{A. Description of the Informant}

The learner providing data on the performance of complimenting speech act is one of the non-English major freshmen in my home university in China. His major is electronic business. He had eight years of English learning experience. He loves studying English very much and his language proficiency is high according to the college entrance examination. He seldom uses English after class and he had no any experience of cross-cultural studies.

\section{B. Questionnaire Design}

In order to achieve the goals of this paper, a questionnaire is designed. First part of it is to introduce the task requirement and to gain general information about the informant. The major content part of the questionnaire, as I mentioned before, which is grounded on the research of Wolfson (1983) and Manes and Wolfson (1981). It is proved to be reliable in eliciting compliments under study considering distance (D) and ranking of imposition(R) factors. Compliments on a dress, a hairdo, ability and skill are four situations which we often do compliments among Chinese people in private or in public.(See the appendix attached)

\section{Data Collection}

The instrument used is a discourse completion test (DCT), originally developed for comparing the speech act realization patterns of native speakers and learners (Blum-Kulka, 1982). The test consists of incomplete discourse sequences that represent socially four differentiated situations. Each discourse begins with a short description of the situation, notifying the speakers' relations to each other, followed by an incomplete dialogue, in which three empty lines are left for the participant to fill in.

The informant was told to read the four situations carefully, ask questions about the task if he cannot understand the literal meaning before started and then elicit his natural response answers to each situation. He was not informed to fill in a compliment speech act. He had to decide what are proper for the blanks in his real situations.

Data were then transcribed and analyzed based on the analytical framework from Manes and Wolfson (1981), which 
is explained in Literature part of this paper.

\section{ANALYSIS}

The learner provided 12 sentences altogether in 12 blank lines. Among them, 10 are considered as compliment patterns referring to the analytical framework with two exclusions.

The data reveals the learner was fully aware of the need of complimenting acts in the blanks. He used very direct compliment in most cases, type 3. "PRO is (really) (a) (ADJ) NP" accounts for $75 \%$ of data (e.g. it is so nice) which indicates the informant favors ADJ pattern in complimenting; "Thank pattern" and "wish pattern" are also provided; "beautiful" and "good" two most frequent adjectives; the main pragmatic strategies he employed included:

1). Upgraders. The learner uses interjections "oh" before compliment in situation one. e.g. "Oh, it's looks very good" and "Oh, it is a pop skirt"; he also upgrades the degree of compliments by emphasizing the key noun phrase; e.g. "It's the fish flavors very delicious."

2). Grounder. The learner offered a reason before compliment in situation three. e.g. "You won this competition glad to you";

3). Suggested devices. The learner offered some suggestions to avoid direct compliment; e.g. "You can wish it very good." and "Eating it feeling very good."

4). Sensitive to D factor. Unlike situation one, two interlocutors in situation two are not so familiar with each other, the informant uses the same pattern of compliments as the former but omit the interjections "oh". e.g. "It's very beautiful." instead of "Oh, It's very beautiful." In grammar, an interjection is used to express a strong feeling, and there is not so strong feeling between non-familiar speakers.

5). Gender difference awareness. The informant is reluctant to give compliments on males in situation three and four that is why data in these two cases are not so formulatic, even including the one to express wishes. e.g. "I wish you have a good time." and "You can wish it very good."

6). Unconscious to $\mathrm{R}$ factor. The informant seems to compliment every topic successfully except some unclear expressions. That is to say, no topic seems to be difficult for him to make a compliment.

\section{DISCUSSION AND CONCLUSION}

\section{A. What could Account for the Informant's Pragmatic Behavior?}

It is very disappointed that although the learner had learnt English for eight years, his language proficiency as well as pragmatic competence remains at the primary level referring to the data.

At first, there are many grammatical mistakes in the data, such as word choice, sentence structure, run-on sentence, punctuations which indicates that the informant don not grasp English language knowledge at a high level though his entrance score is quite satisfactory. Besides, the restricted compliment realization pattern (i.e. Type 3. account for 75\%) further showed that he does not acquire enough language knowledge about how to compliment others. And the data he provided are very short and merely no modification, which according to Takahashi and Beebe (1993) is very typical of second language learners who are lacking in fluency and proficiency in the target language.

On the other hand, the informant himself has inadequate awareness of culture differences. The data which are out of formula and the ones which slightly aware that there is D, R between interlocutors can offer some evidence; moreover, the informant uses very few politeness strategies on complimenting also indicates that his poor understanding of pragmatic knowledge.

\section{B. Suggested Pedagogical Implication}

The above discussion provides evidence to increase learner's communicative competence from grammatical competence, strategic competence and sociolinguistic competence (i.e. pragmatic competence) three aspects (Canale \& Swan, 1980).

1).The improvement of grammatical competence requires EFL teachers to reconsider our cultivation goal of English courses. Can all of the students have solid control of English knowledge? The problems associated with existing text selections and teaching methods mean that the stated course aims are rarely fulfilled.

Input courses, like listening and reading can be exposed to students anywhere and anytime with diversity styles; more practical courses, like writing, translation, and speaking offered to students to practice in order to reinforce their language abilities. The materials for teaching should be authentic and up-dated. Besides the texts for the aim of passing certain kinds of examinations, teacher should choose more authentic supplementary materials to motivate students to learn more. Traditional grammar approach of teaching should be challenged; Teaching is the main means for gaining knowledge. The way of traditional teaching should be converted into communicative teaching based on real tasks - focus on meaning. The role of a teacher should be changed to counselor and helper whereas students are actors and speakers. They will be more active if they take the central role in class.

2). The improvement of strategic competence requires more exposure to the target English and intercultural communications. When EFL learner study a foreign language, one big problem is that they do not have enough exposure to target language. In Chinese context, mother language is the most influential element that makes effective 
communication a dream beyond reach. Pragmatic failure emerged due to the miscommunication of pragmatic transfer, especially negative transfer of L1. Enhancement of cultural sensibility plays an important role in improving EFL learners' strategic competence. Moreover, Social changes and the cross-cultural communication threaten to intensify the awareness of culture. Increase the possibility of cross-cultural experiences is an effective way to provide with the learner for more opportunities to observe native speakers' pragmatic behaviors, and it helps to decrease students' pragmatic failures so as to achieve successful communication.

3 ). the improvement of sociolinguistic competence (pragmatic competence) requires explicit and implicit teaching of pragmatic knowledge.

The aim of second language learning is to use the language appropriately in different contexts, so meta-pragmatic competence should be put forward. According to Kasper (2001), pragmatic competence can be taught in classroom. Therefore, explicit teaching of Speech Act Theory and how to use these acts should be given to the students. Some theories on pragmatics strategies such as Leech's politeness principle as well as Brown \& Levinson's face view, Gu's model of politeness need to be expounded in order to make the learner aware there are great differences in realizing speech acts as requesting, complimenting, and apologizing in Chinese and English contexts. These theories are well-accepted as the overriding communication principles and that they reflect the characteristics of Anglo-Saxon culture. When the learners are conscious of such culture differences, implicit teaching is necessary, their pragmatic competence can be raised gradually through practicing.

To sum up, pragmatics should be taken into one required course for EFL learners because "In order to communicate successfully in a target language, pragmatic competence in L2 must be reasonably well developed”(Kasper, 1997, p.2).

\section{Limitations of this Study}

Under-effective DCT: DCT has its own disadvantages which the informant was imposed a lot to give her compliments. No matter he likes or not, she must elicit natural, spontaneous responses from the four situations.

Insufficient situations: more situations should be added to the questionnaire that can elicit compliments in English speaking countries

Small sample: investigation on one person is too limited. The data we get is typical on this informant which does not mean the whole English major students are in this case. Hundreds of sample can offer reliable data in this empirical study.

On the whole, this study aims to raise cross-cultural pragmatic awareness by analyzing complimenting speech acts, further researches can be done to explore classroom pragmatic implications, speech acts in particular in Chinese EFL contexts.

\section{REFERENCES}

[1] Austin, J. L. (1962). How to Do Things with Words. Oxford: Oxford University Press.

[2] Blum-Kulka, S. (1982). Learning how to say what you mean in a second language: A study of speech act performance of learners of Hebrew as a second language. Applied Linguistics, 3: 29-59.

[3] Brown, P. \& Levinson, S. (1987). Politeness: Some Universals in Language Usage. Cambridge: Cambridge University Press.

[4] Chen, R. (1993). Responding to compliments: A contrastive study of politeness strategies between American English and Chinese speakers. Journal of Pragmatics, 20: 49-75.

[5] Canale, M. \& Swain, M. (1980). "Theoretical bases of communicative approaches to second language teaching and resting". Applied Linguistics 1, pp.1-47.

[6] Gu, Y. G. (1990). Politeness phenomena in modern Chinese. Journal of Pragmatics, 14: 237-257.

[7] Han, C. (1992). A comparative study of compliment responses: Korean females in Korean Interactions and in English interactions. Working Papers in Educational Linguistics. 8: 17-31.

[8] Holmes, J. (1988). Paying compliments: A sex-preferential politeness strategy. Journal of Pragmatics, 12: 445-465.

[9] Leech, G. N. (1983). Principles of Pragmatics. New York: Longman Group Limited.

[10] Kasper, G. (1997). Can pragmatic competence be taught? Retrieved 25/11, 2010, from Dr. Minh's PPT Slides, p.2.

[11] Kasper, G. (2001). "Classroom research on interlanguage pragmatics". In Kenneth R. Rose \& G. Kasper (eds.) Pragmatics in Language Teaching, 2001, pp.33-60. Cambridge: Cambridge University Press.

[12] Manes \& Wolfson. (1981). The compliment formula. In F. Coulmas (ed.), Conversational Routine, pp.115-132. The Hague: Mouton.

[13] Searle, J. (1975). Indirect Speech Acts. In P. Cole \& J. Morgan (eds.), Syntax and Semantics 3: Speech Acts. New York: AP.

[14] Takahashi, T. and Beebe, L. M. (1993). Cross linguistic influence in the speech act of correction. In G. Kasper and S. Blum-Kulka (Eds) Interlanguage pragmatics. New York: Oxford University Press. 138-157.

[15] Wolfson, N. (1983). An Empirically Based Analysis of Compliments. In N. Wolfson \&E. Judd (eds.), Sociolinguistics and Language acquisition, Rowley, MA: Newbury House. 82-95.

[16] Wolfson, N. (1988). The Bulge: A theory of speech behavior and social distance. In Fine, J. (ed.), Second Language Discourse: A textbook of current research. Norwood, NJ: Able.

Yuanbing Duan was born in Yuanyang, Yunnan, China in 1978. She received her M.A. degree in linguistics from Yunnan Normal University, China in 2006 and now she is a $\mathrm{PhD}$ candidate in Shanghai International Studies University, China. 
She is currently a lecturer in the School of Arts and Science, Yunnan Radio and TV University, Kunming, China. Her research interests include Pragmatics and English Teaching Methodology.

Ms. Duan is a member of the Yunnan Association of Foreign Language Teachers. 